\title{
Bilateral Internal Thoracic Artery Bypass Grafting in a High Risk Population - A Four Year Experience with STS Database Derived Clinical Outcomes
}

\author{
John Jeffrey Tyner ${ }^{1, *}$, Kate Jensen ${ }^{1}$, Alexander Conkey Tyner², Ashley Jaravata ${ }^{3}$ \\ ${ }^{1}$ Prebys Cardiovascular Institute, San Diego, USA \\ ${ }^{2}$ Applied Physics, Northwestern University, Evanston, USA \\ ${ }^{3}$ Clinical Care Lines, Scripps Hospital, San Diego, USA
}

\section{Email address:}

jjt@sbcglobal.net(J. J. Tyner), Katejensen0905@gmail.com (K. Jensen), alextyner@gmail.com (A. C. Tyner)

${ }^{*}$ Corresponding author

\section{To cite this article:}

John Jeffrey Tyner, Kate Jensen, Alexander Conkey Tyner, Ashley Jaravata. Bilateral Internal Thoracic Artery Bypass Grafting in a High Risk Population - A Four Year Experience with STS Database Derived Clinical Outcomes. Journal of Surgery.

Vol. 7, No. 6, 2019, pp. 158-162. doi: 10.11648/j.js.20190706.12

Received: July 14, 2019; Accepted: October 5, 2019; Published: October 24, 2019

\begin{abstract}
The purpose of this retrospective review was to examine the morbidity and mortality associated with the routine use of skeletonized bilateral internal thoracic arteries (BITA) in coronary bypass surgery (CABG). The current rate of BITA use is reported to be $5 \%$ in the US. The literature reflects an increased incidence of wound complications, especially in obese, diabetic, and female patients. Our policy has been to use skeletonized BITA in patients regardless of comorbidities. Using the Society of Thoracic Surgery (STS) database, the postoperative markers of prolonged ventilation (PV), length of stay (LOS), wound infection, death, and 30 day readmission were evaluated for all isolated coronary bypass operations (isocab) to allow comparison of bilateral and single internal thoracic artery (ITA) use during this four year period. The incidence of BITA use was $60 \%$. The groups had similar comorbities and postop complications were similar regardless of single or bilateral thoracic artery use. Specifically, there were no wound complications in the BITA group. Adjuncts such as ITA skeletonization, platelet rich plasma, negative pressure wound dressing, and absence of bone wax were utilized in all cases. The added expense is justified to allow the expanded use of BITA.
\end{abstract}

Keywords: Coronary Bypass, Skeletonized Internal Thoracic Arteries, Bilateral Internal Thoracic Arteries, Wound Complications, Platelet Rich Plasma, Negative Pressure Wound Dressing

\section{Introduction}

It is recognized that multiple arterial grafts are preferable in coronary operations. [6, 7] Despite this, bilateral thoracic artery (BITA) use occurs in approximately $5 \%$ [1] of isolated coronary operations performed in the US. This is felt to be due to concerns for surgical complications, primarily wound infection. Furthermore, it adds time to the procedure, and there is no quality metric associated with it. It has been our policy to use BITA grafting in all patients for whom we can use both in continuity, not as a free graft. This is without regard to obesity, diabetes, or female sex. All factors associated with increased wound complications. [2-5] To offset this risk, several adjuncts were utilized. In addition to skeletonizing all internal thoracic arteries (ITA), no bone wax was used, platelet rich plasma (PRP) was applied to the sternal edges prior to closure, and negative wound pressure dressings were used. (PrevenaTherapy, Kinetic Concepts Inc. San Antonio Texas, USA). All of these add expense. This was felt to be acceptable if they permitted safe extended use of BITA grafting.

\section{Methods}

With IRB approval, from the STS database we reviewed a single surgeon's isocab cases from 2104 to 2017. The patients were placed in two groups, single and bilateral 
internal thoracic artery use. Their preoperative characteristics of diabetes, sex (male/female), and obesity were identified. Postoperative complications of death, wound infection, prolonged ventilation (PV), 30 day readmission, and length of stay (LOS) were all retrieved from the STS database according to the established definitions. [8] We then evaluated the two groups for preoperative comorbidities, and postoperative outcomes.

\section{Results}

During this period from 2014 through 2017, 225 patients underwent isocab (Figure 1). Males were 88\%, 41\% were diabetic and $30 \%$ were obese (Figures 2, 3). Of this group, $61 \%$ received BITA (Figure 4 ).

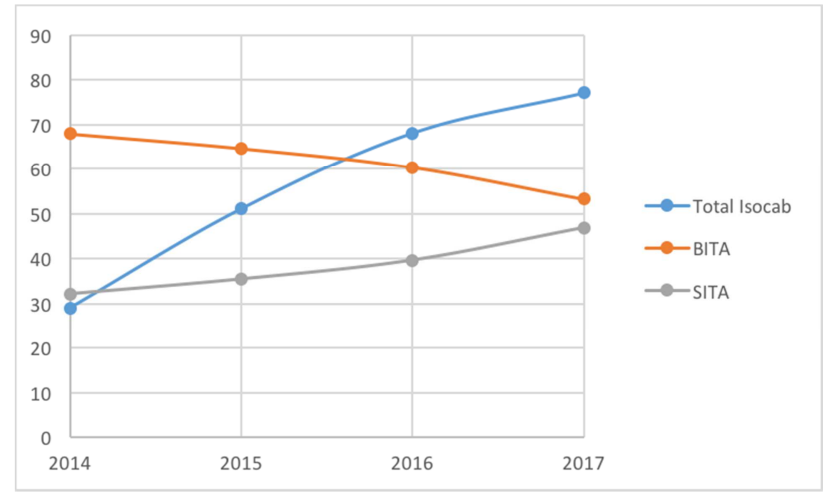

Figure 1. Isocab BITA/SITA.

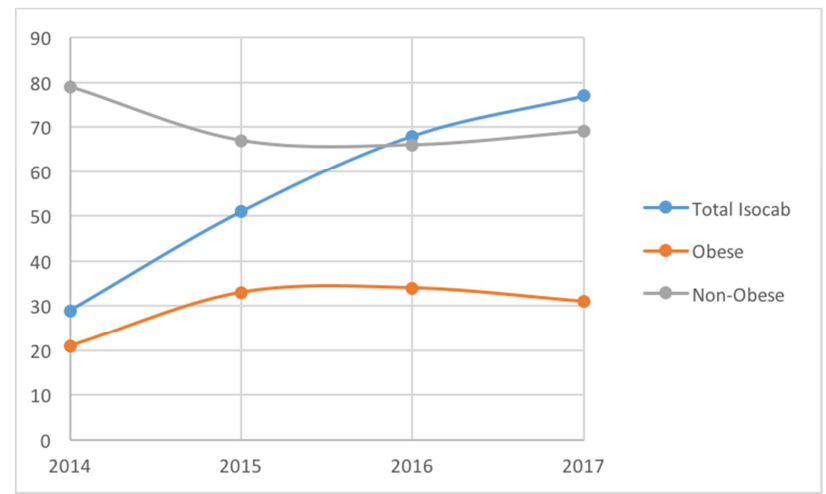

Figure 2. Isocab Diabetic/Non-Diabetic.

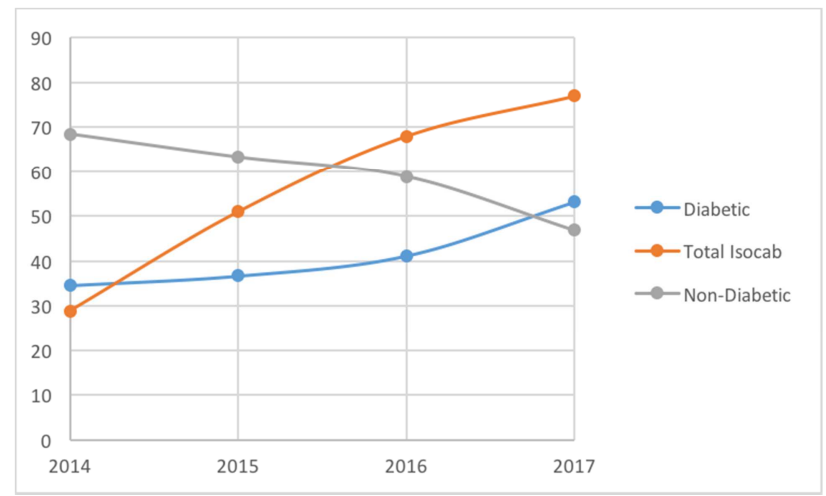

Figure 3. Isocab BITA/SITA.

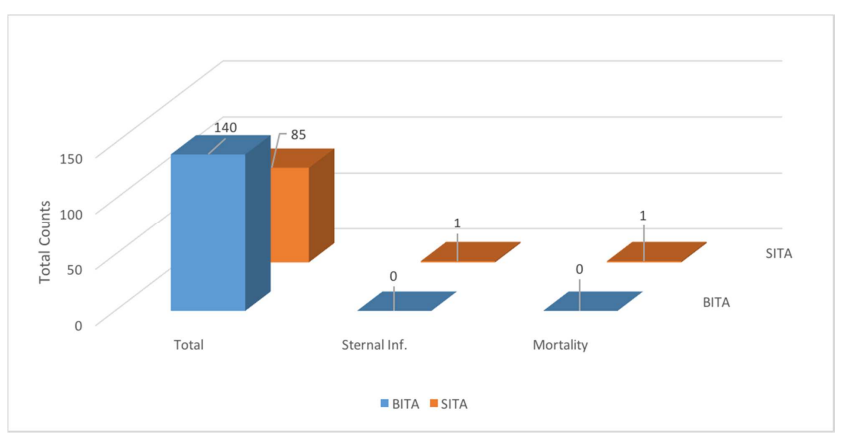

Figure 4. Isocab 2014-2017.

There was one mortality and one sternal infection, both occurred in the single ITA group. There were no differences in prolonged ventilation (PV) or length of stay (LOS) (Figures 5,6).

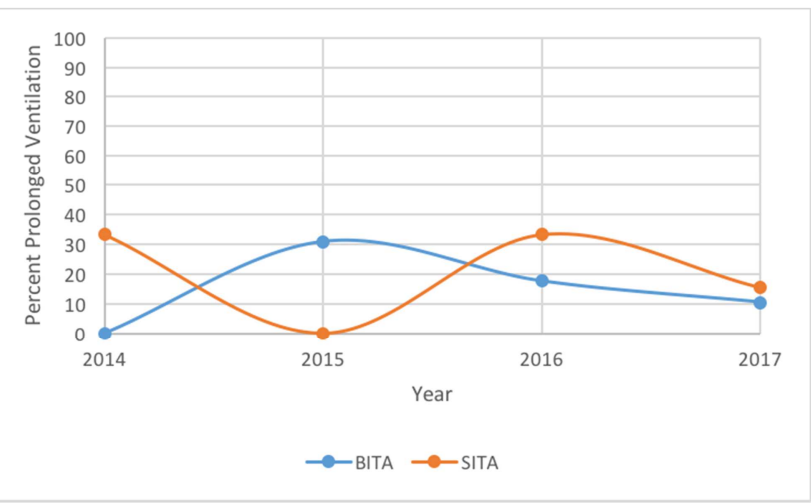

Figure 5. Prolonged ventilation.

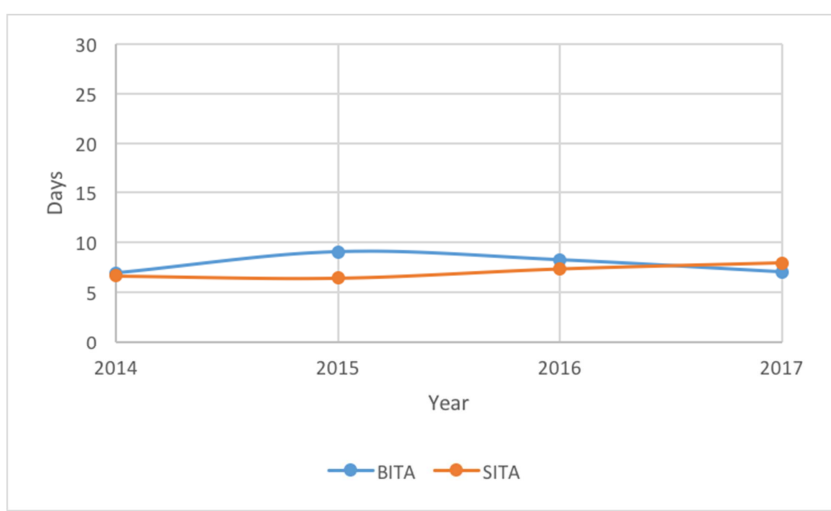

Figure 6. Average post-op length of stay.

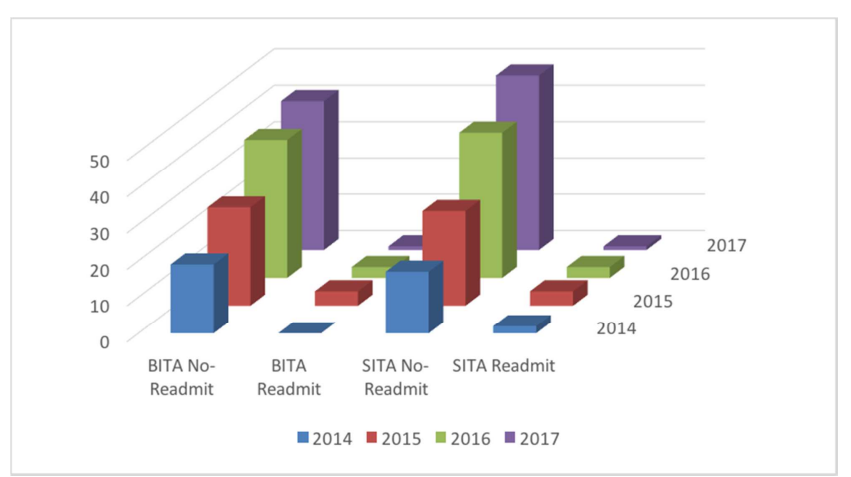

Figure 7. Isocab readmit count. 
The 30 day readmission rate was $6.1 \%$ for BITA and $9 \%$ for single thoracic artery (SITA). (Figure 7)

\section{Discussion}

Unlike left internal thoracic artery use in CABG, it has not been proven that the use of BITA adds further patient longevity. [6, 7, 9] Nonetheless, there is sustained and growing enthusiasm for use of multiple arterial grafts. In spite of this, in the United States, the utilization is low at 5\%. Most of the concerns are due to the incidence of wound complications and the associated morbidity, mortality, and expense associated with this problem. $[10,11] \mathrm{CABG}$ is one of the most scrutinized operations in the history of surgery, not to mention the advent of public reporting. Understandably, few surgeons want to invite the potential for increased complications especially in light of the fact that the STS does not attach an improved quality metric for BITA and there is no financial incentive. In fact it can have a negative incentive as it adds more operative and anesthesia time to the case. To mitigate the risks of wound complications several modifications were made to the procedure. Specifically, four additions were incorporated.

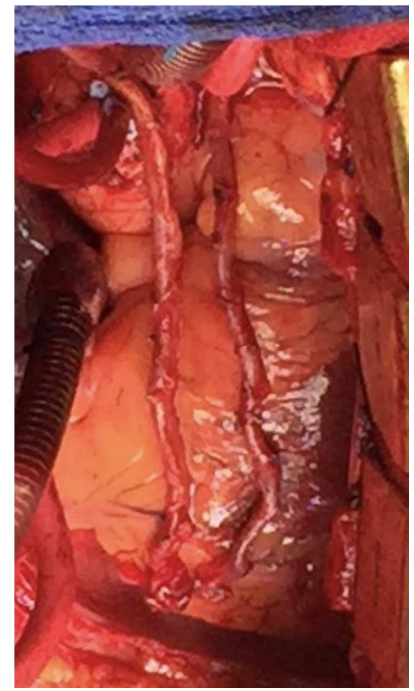

Figure 8. Skeletonized bilateral internal thoracic arteries.

The use of internal thoracic arteries as skeletonized conduits versus pedicle grafts is felt to be helpful with regard to sternal healing. Studies have demonstrated reduced sternal devascularization in multiple evaluations. [12, 13] The technique involved dissecting the internal thoracic artery as a single arterial conduit from the chest wall without taking the surrounding tissue pad or accompanying veins. As opposed to the use of a monopolar cautery, this is accomplished with metallic clips, a bipolar device and scissors. Due to proximity to the arterial graft, a monopolar device results in excess heat transfer and possible subsequent injury to the conduit. Papaverine is used topically to minimize vaso-spasm. At the termination of the internal thoracic artery takedown, prior to heparinization, it is clipped distally and wrapped in papaverine soaked sponge to allow it to dilate while preparations for bypass are carried out. They appear as shown in figure 8. Additional benefits of skeletonization are increased length and flow. $[14,15]$

If our goal is to provide the safe and increased use of multiple arterial grafts and skeletonization would seem to be fundamental to this effort. In addition to the observed benefit of increased sternal vascularity post harvest, the clinical outcomes using skeletonized conduits also support the use. In diabetics, often best served with coronary bypass surgery, especially young patients, the reduced risk of sternal complications associated with skeletonization seem to support the extra time and care required for this technique. Except for the potential increased operative time there is no additive expense for this adjunct.

The use of negative wound pressure dressings has been reported to reduce sternotomy infection in a high risk group of obese patients. $[17,18]$ The incidence of wound infection was significantly reduced in negative pressure wound dressing patients with BMIs equal to or greater than 30 . The theory is that skin breakdown allows incisional seepage of skin flora and subsequent infection. Negative pressure dressing support the healing incision to minimize separation and prevent the accumulation of surrounding fluids with associated skin bacteria. Furthermore, it is felt to improve microcirculation, promote tissue proliferation, improve lymphatic drainage and reduce wound stress. The device used, Prevena Therapy, (Kinetic Concepts Incorporated, San Antonio Texas, USA) is applied in the operating room, prior to drape removal on a sterile closed incision. It is removed to discharge or at 8 days. The dressing is connected to a batterypowered device, small enough to place in a hospital gown pocket, with a fluid collection canister incorporated. It applies approximately $-125 \mathrm{mmHg}$ pressure to the incision. We have not noticed any device related complications. The hospital cost is $\$ 386.10$.

Other modalities utilized to mitigate wound complications include platelet rich plasma. Platelet rich plasma requires 50 cc of blood to be withdrawn then placed in a centrifuge where it is separated into 3 layers, platelet rich plasma, platelet poor plasma, and red blood cells. Prior to application topical bovine thrombin is added to produce a platelet gel. This is aerosolized over the cut edges of the sternum at the termination of the procedure. This gel has a platelet concentration 3-5 times that of native plasma. [19, 20] In addition to having a role in hemostasis, this is a source of growth factors. This includes platelet derived growth factor, insulin like growth factor, vascular endothelial growth factor, and transforming factor beta. [21] In addition, platelets release other substances such as fibronectin and vitronectin both important in wound healing. Due to the nature of the preparation it is felt these factors are found in increased concentrations. All of these facilitate wound healing by increased chemotaxis, proliferation, differentiation, and angiogenesis. [22] This is an autologous preparation which eliminates concerns of cross-reactivity, immune reaction and disease transmission. Most of the studies regarding clinical use of platelet rich plasma are from the orthopedic and oral 
maxillofacial specialties. [23, 24] In these specialities the addition of platelet rich plasma has been felt to support angiogenesis and osteogenesis. Furthermore platelet rich plasma has been felt to enhance bone regeneration in dental and maxillofacial procedures. [25] There are no controlled trials to prove a positive impact. The goal of this evaluation was to augment local wound healing in what has been considered a relatively hostile environment, obese, diabetics with bilateral internal mammary artery harvesting. We have not noticed a negative impact from the use of platelet rich plasma and due to the low expense and ready availability we will plan to continue its use while awaiting other scientific support. The hospital cost is $\$ 50.88$ and it is prepared by the perfusionists prior to commencing bypass.

As an aid to sternal edge hemostasis bone wax has been used extensively in the past. Made from softened beeswax, it is easy to use and effective at tamponading bleeding sternal edges. However it has been shown to inhibit bone healing, stimulate chronic inflammatory reactions, increased infection rates inhibit the ability to clear bacteria. [26] To that end, in an expert consensus review the recommendation is that bone wax not be used in a sternotomy patient. [27] In this series, Hemasorb (Abyrx, Irvington, NY) was utilized for sternal edge hemostasis. It has a putty-like consistency, easy to apply, with reabsorption in 30 days. It provides hemostasis throughout the procedure. It is one of several absorbable hemostatic products on the market for sternal edge hemostasis.

The purpose of this retrospective review was not to support longevity benefits of BITA, but to demonstrate that with certain adjuncts it is possible to safely perform BITA on what are considered to be high risk patients. These additional components come at a cost. The addition of PRP, Hemasorb, and negative wound dressings add approximately $\$ 750$ to each case. In this review 132 patients received BITA. The incidence of wound complications for this group is reported to be from $2 \%-5 \%$. [6] The BITA group did not have any wound complications. Assuming a conservative wound complication rate of $2 \%$, at a cost of at least $\$ 60,000$ for each sternal complication, the unreimbursed cost for this predominantly Medicare population would be $\$ 158,000$. [10] This is a conservative estimate that would nonetheless cover the cost of above mentioned wound precautions.

\section{Conclusion}

Two things are clear. There should be more of an incentive to use both thoracicarteries or at least multiple arterial grafts. The STS database should recognize this effort with a quality metric. Secondly, surgeons are often evaluated on a cost basis without giving clear thought to the rationale and quality benefits these costs can accrue. If multiple arterial grafts are our goal as coronary surgeons, this review supports their use in a wider spectrum of patients, previously thought to be high risk. The added expense justified with the goal of providing superior coronary surgery for our patients.

\section{References}

[1] Tabata M, Grab JD, Khalpey z, Edwards FH, O'Brien SM, Cohn LH, et al. Prevalence and variability of internal mammary artery graft use in comtemporary multivessel coronary artery bypass graft surgery, Circulation. 2009; 120: 935-40.

[2] Katharina Meszaros, MD, Urs Fuehrer, MD, Sina Grogg, MD, Gottfried Sodeck, MD, Martin Czerny, MD, Jonas Marschall, MD, and Thierry Carrel, MD, Risk Factors for Sternal Wound Infection After Open Heart Operations Vary According to Type of Ooperation, Ann Thorac Surg 2016; 101: 1418-25.

[3] Priyadharshanan Ariyaratnam, Martin Bland, Mahmoud Loubani, Risk factors and mortality associated with deep sternal wound infections following coronary bypass surgery with or without concomitant procedures in a UK population: a basis for a new risk model?, J Interactive CardioVascular and Thoracic Surgery 11 (2010) 543-546.

[4] Michael A. Borger, MD, Vivek Rao, MD, Richard D Weisel, MD, Joan Ivanov, MSc, Gideon Cohen, MD, Hugh E. Scully, MD, and Tirone E. David, MD, Deep Sternal Wound Infection: Risk Factors and Outcomes, Ann Thorac Surg 1998; 65: 1050-6.

[5] Sulakshana Balachandran, $\mathrm{PhD}$, Annemarie Lee, PhD, Linda Denehy, PhD, Kuan-Yin Lin, MS, Alsstair Royse, MBBS, MD, Colin Royse, MBBS, MD, and Doe El-Ansary PhD, Risk Factors for Sternal Complications after Cardiac Operations: A systematic Review, Ann Thorac Surg 2016; 102: 2109-17.

[6] Taggart DP, D'Amico R, Altman DG. Effect of arterial revascularisation on survival: a systematic review of studies comparing bilateral and single internal mammary arteries. Lancet. 2001; 358: 870-5.

[7] Yi G, Shine B, Rehman SM, Altman DG, Taggart DP. Effect of bilateral internal mammary artery grafts on long-term survival: a meta-analysis aproach. Circulation. 2014; 130: 539-45.

[8] Society of Thoracic Surgeons Adult Cardiac Surgery Database, Version 2.9.

[9] Loop FD, Lytle BW, Cosgrove DM, Stewart RW, Goormastic $\mathrm{M}$, Williams GW, et al. Influence of the internal mammary artery graft on 10 year survival and other cardiac events. N Engl J Med. 1986; 314: 1-6.

[10] Damien J LaPar, MD, MSc, Ivan Crosby, MD, Jeffrey Rich, et al. A Contemporary Cost Analysis of Postoperative Morbidity After Coronary Artery Bypass Grafting With and Without Concomitant Aortic Valve Replacement to Improve patient Quality and Cost-Effective Care. Ann Thorac Surg 2013; 96: 1621-7.

[11] Karolin Fraf, Ella Ott, Ralf-Peter Vonberg, Christian Kuehn, Axel Haverich, Iris Freya Chaberny, Economics of deep sternal wound infections, European Journal of CardioThoracic Surgery, Volume 37, Issue 4, Aprio 2010, pages 893896.

[12] Hiroyuki Kamiya, MD, Payam Akhayari, MD, et al. Sternal Microcirculation after skeletonized versus pedicled harvesting of the internal thoracic artery: A randomized study. J Thorac Cardiovasc Surg 2008; 135: 32-7. 
[13] Munir Boodhwani, MD, MMSc; B. Khanh Lam, MD; Howard Nathan, MD' et al. Skeletonized Internal Thoracic Artery Harvest Reduces Pain and Dysesthesia and Improves Sternal Perfusion after Coronary Atery Bypass Surgery. Circulation. 2006; 114: 766-773.

[14] Yoshiyuki Takami, MD, Hiroshi Ina MD, Effects of Skeletonziation on Intraoperative Flow and Anastomossi Diameter of Internal Thoracic Arteries in Coronary Artery Bypass Grafting. Ann Thorac Surg 2002; 73: 1441-5.

[15] Marek A. Deja, MD, Stanislaw Wos, MD, Krzysztof S. Gplba, $\mathrm{MD}$, et al. Intraoperative and Laboraory Evaluation of Skeletonized Versus Pedicled Internal Thoracic Artery. Ann Thorac Surg 1999; 68: 2164-8.

[16] Xiang $\mathrm{Hu}, \mathrm{PhD}$, and Qiang Zhao, MD, Skeletonized Internal Thoracic Artery Harvest Improves Prognosis in High Risk Population After Coronary Artery Bypass Surgery for Good Quality Grafts, Ann Thorac Surg 2011; 92: 48-58.

[17] Onnen Grauhan, MD, PhD, MBA, Artashes Navasardyan, Michael Hofmann, MD, et al., Prevention of poststernotomy wound infections in obese patients by negative pressure wound therapy. J Thoracic Cardiovasc Surg 2013; 145: 138792.

[18] Pascal M. Dohmen, Thanasie Markou, Richar Ingemansson, et al., Use of Incisional Negative Pressure Wound Therapy on Closed Median Sternal Incisions after Cardiothoracic Surgery: Clinical Evidence and Consensus Recommendations. Med Sci Monit, 2014; 20: 1814-1825.

[19] Marx RE, Carlson ER, Eichstaedt RM, et al., Platelet - rich plasma: Growth factor enhancement for bone grafts. Oral Surg Oral Med Oral Pathol Oral Radiol Endod 1998; 85: 638-6464.
[20] Petrungaro PS, Using platelet-rich plasma to accelerate soft tissue maturation in esthetic periodontal surgery. Compend Contin Educ Dent 2001; 22: 729-732.

[21] Nasir Hussain, Hernan Johal, Mohit Bhandari. An evidencebased evaluation on the use of platelet rish plasma in orthopedics- a review of the literature. SICOT J 2017, 3, 57.

[22] Bennett NT, Schultz GS. Growth facter and wound healing: biochemical properties of growth facter and their receptors. Am J Surg 1993; 165: 728-737.

[23] Lucarelli E, Donati D, Cenacchi A, Forasari PM. Bone reconstruction of large defects using bone marrow derived autologous stem cells. Transfus Apher Sci 2004; 30: 169-74.

[24] Hanna R, Trejo PM, Weltman RL. Treatment of intrabony defects with bovine derived xenograft alone and in combination with platelet-rich plasma: a randomized clinical trial. J Periodontol 2004; 75: 1668-1677.

[25] Kim SG, Chung CH, Kim YK, Park JC, Lim SC. Use of particulate dentin-plaster of Paris combination with /without platelet -rich plasma in the treatment of bone defects around implants. Int J Oral Maxillofac Implants 2002; 17: 86-94.

[26] Tadeusz Wellisz, MD, Jonathan K Armstrong PhD, John Cambridge $\mathrm{PhD}$, et al., the Effects of a Soluble Polymer and Bone Wax on Sternal Healing in an Animal Model. Ann Thorac Surg 2008; 85: 1776-80.

[27] Harold Lazar, MD, Thomas Vander Salm, MD, Richard Engelman, MD, et. al., Prevention and management of sternal wound infections. J Thorac Cardiovasc Surg 2016; 152: 96272 . 